\title{
Caso clínico: Intususcepción intestinal con protrusión ano-rectal en caninos
}

\author{
Clinical case: Intestinal Intussusception with ano-rectal protrusión in canine
}

\author{
Eliana Neira-Martínez ${ }^{1 *}$ (D), Ricardo Céspedes-Quintero² (iD, Diego Fernando Pardo-Santamaría ${ }^{1}$ (D) \\ Carol Melisa González-Aranguren ${ }^{1}$
}

\author{
${ }^{1}$ Universidad de Boyacá. Tunja, Boyacá, Colombia. ²Universidad Pedagógica y Tecnológica de Colombia. Tunja, Boyacá, Colombia. \\ Correo electrónico: elineira@uniboyaca.edu.co
}

\section{RESUMEN}

Se describe el caso específico y poco común, presentado en una clínica veterinaria de la ciudad de Tunja (Boyacá - Colombia), respecto a la intususcepción o invaginación del colón con protrusión ano-rectal en canino, posterior a una semana de hospitalización con diagnóstico primario "gastroenteritis de origen viral", de 6 meses de edad, raza criolla; la historia clínica no detalla antecedentes clínicos ni quirúrgicos; luego del proceso quirúrgico sin complicaciones muere con diagnóstico de isquemia de repercusión posquirúrgica. Este caso clínico pretende aportar a la literatura científica, información en relación de la medicina veterinaria quirúrgica.

Palabras clave: Intususcepción; invaginación; protrusión ano-rectal

\begin{abstract}
The specific and unusual case presented in a Veterinary clinic in the City of Tunja (Boyacá - Colombia) was described, regarding intussusception or invagination of the colon with anorectal protrusion in canine, after one week of hospitalization with primary diagnosis "gastroenteritis of viral origin", in a 6-month-old, Creole breed;the medical history does not detail clinical or surgical history. After the surgical process without complications, the animal dies with a diagnosis of ischemia of postoperative repercussion. This clinical case aims to contribute to the scientific literature in relation to surgical veterinary medicine.
\end{abstract}

Key words: Intussusception; invagination; anorectal protrusion 


\section{INTRODUCCIÓN}

La intususcepción o invaginación intestinal es definida como la introducción de una porción intestinal en la luz intestinal del segmento inmediatamente distal al mismo. La porción invaginada puede afectar distintos tramos del tracto gastrointestinal (TGI), siendo las más comunes las intususcepciones ileocólicas y yeyunoyeyunales [2]; de otro lado, Patsikas y col. [9] describen a la intususcepción como la invaginación de un segmento intestinal (intussusceptum), dentro del lumen de un segmento adyacente (intussuscipiens); la cual está asociada a hipermotilidad por enteritis (parasitismo, infección viral o bacterial), indiscreción dietaria, cuerpos extraños, masas y cicatrices [9].

Las alteraciones gastrointestinales son patologías que pueden comprometer en alto porcentaje la vida de los pacientes, por lo que deben ser tratadas con urgencia y de la manera más adecuada y rápida; sin embargo, hay casos donde la sintomatología del paciente no es clara provocando demoras en la atención y desenlaces fatales para el paciente $[7,10]$

Lucena y Giles [5] indicaron que el prolapso rectal puede producirse en animales jóvenes en mal estado, con parásitos, asociado a tumores en gatos (Felis catus) mayores, y tras la reparación de una hernia perineal en los perros (Canis lupus). Los signos clínicos son obvios, pero es necesario distinguir el prolapso de ano y recto con invaginación del íleon. El prolapso de ano se debe resecar en caso de necrosis. En otros casos, es posible reducir el recto prolapsado [5].

La intususcepción o invaginación intestinal puede formar parte de las urgencias del TGI y aunque es poco frecuente debe ser tratado de una manera adecuada y teniendo en cuenta principalmente sus signos clínicos, identificando la naturaleza del problema y decidiendo si la cirugía está realmente indicada o no para el caso a tratar de inmediato $[3,6]$.

El presente caso clínico refiere un canino que presentó intususcepción intestinal con prolapso ano-rectal, 6 días (d) después de ingresar al centro de atención y tuvo como desenlace final la muerte.

\section{MATERIALES Y MÉTODOS}

\section{Anamnesis}

Paciente canino, sexo macho de aproximadamente 6 meses de edad, raza criolla, color negro, con peso de 4,70 kilogramos (kg), que respondía al nombre de Docky, ingresado en el centro de atención veterinario con signos clínicos de diarrea, vómito, aspecto deprimido e inapetente. A la valoración clínica, el paciente se encontró tranquilo, con un temperamento dócil y sin apetito, su propietaria no reportó carnet de vacunas, ni tampoco se evidenciaron antecedentes clínicos o quirúrgicos, por lo cual se generó el diagnóstico presuntivo de gastroenteritis de origen viral y diagnósticos diferenciales de parvo-virosis, moquillo y coronavirus.

\section{Clínica}

Dentro de su evolución clínica se decidió hospitalizar al paciente con la siguiente medicación: Metronidazol 20 miligramos (mg) $\mathrm{kg}^{-1}$ cada 12 horas (h), Ampicilina sulfatan, $20 \mathrm{mg} \cdot \mathrm{kg}^{-1}$ cada $8 \mathrm{~h}$, Fluimucil $300 \mathrm{mg} \cdot \mathrm{kg}^{-1}$ cada $24 \mathrm{~h}$ Quercetol $1,4 \mathrm{mg}$ cada $6 \mathrm{~h}$, atropina $0,22 \mathrm{mg} \cdot \mathrm{kg}^{-1}$ cada $6 \mathrm{~h}$, Ondacetron $0,2 \mathrm{mg} \cdot \mathrm{kg}^{-1}$ cada $24 \mathrm{~h}$ y Ranitidina $4 \mathrm{mg} \cdot \mathrm{kg}^{-1}$ cada $6 \mathrm{~h}$. Transcurrido seis d de hospitalización se evidenció que presentaba invaginación intestinal y prolapso rectal completo, por lo que se decide trasladar de urgencia a salas de cirugía.

\section{Procedimiento quirúrgico}

\section{Protocolo anestésico}

Al ingreso a salas de cirugía se realizó el proceso de verificación y planeación de insumos médico quirúrgicos por el personal de instrumentación quirúrgica, se elaboró la lista de chequeo para controlar el ingreso y la seguridad de la cirugía dentro del procedimiento, el paciente ingresó a quirófano canalizado y rasurado de acuerdo al protocolo establecido para procedimiento de laparotomía.

Se colocó el paciente en posición de cubito supino y se le realizó inducción anestésica con xilacina $1,1 \mathrm{mg} \cdot \mathrm{kg}^{-1}$; ketamina $10 \mathrm{mg} \cdot \mathrm{kg}^{-1}$ y para el mantenimiento anestésico se utilizó propofol $2 \mathrm{mg} \cdot \mathrm{kg}^{-1}$, se realizó asepsia y antisepsia del área operatoria con yodopovidona solución, se colocaron los campos estériles en el área operatoria y se realizó conteo inicial de compresas, gasas, agujas e instrumental quirúrgico para dar inicio a la intervención.

\section{Desarrollo del proceso quirúrgico}

Se realizó una incisión abdominal mediana en piel con hoja de bisturí \# 15, se realizó disección de la vaina lateral y medial del musculo recto del abdomen y el peritoneo, culminada la disección se observó que la invaginación comprometía las 3/4 partes del intestino grueso y que protruye a través del ano (FIG. 1).

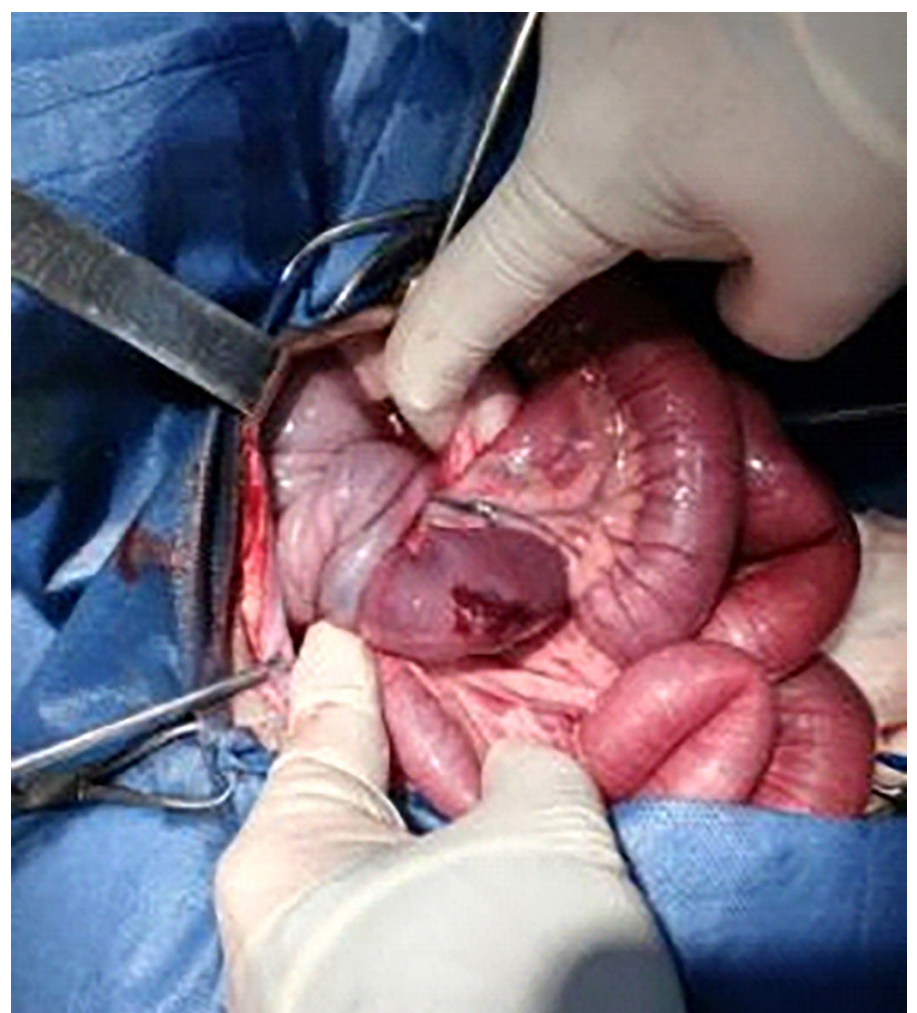

FIGURA 1. Porción del intestino grueso comprometido y protrusión anal 
Se realizó maniobra para reducir el intestino por la zona abdominal sin respuesta alguna, por lo que se realizó reducción por zona perineal por parte del cirujano, mientras que el ayudante hizo la reducción por zona abdominal (FIG. 2).

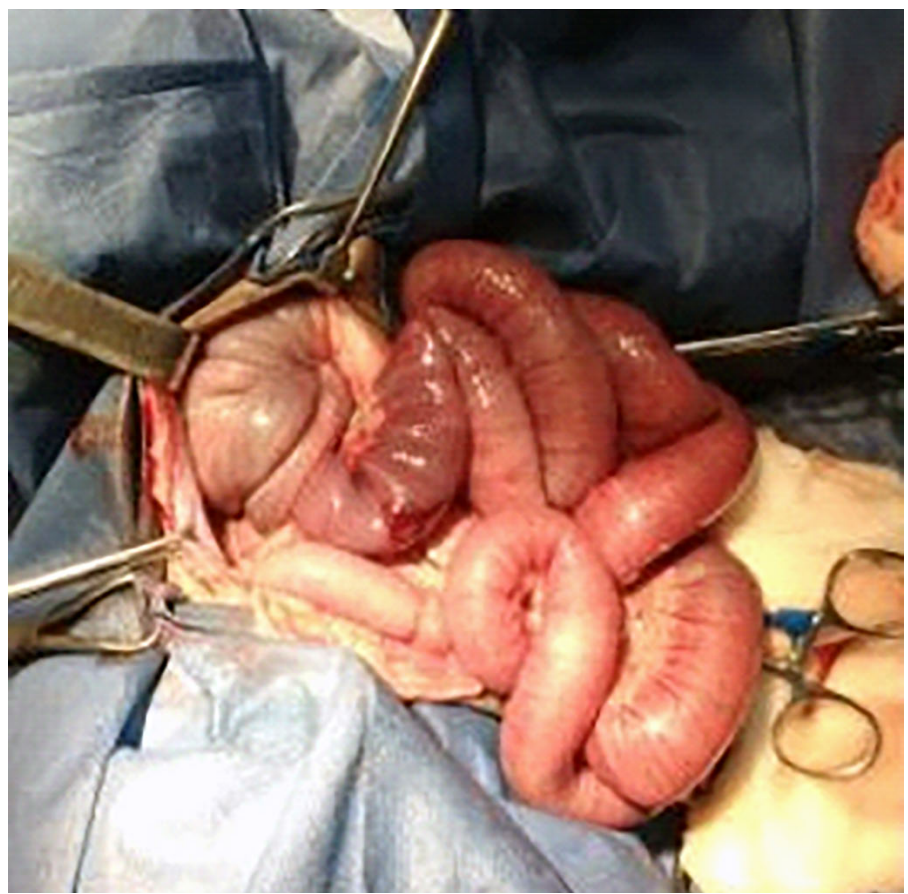

FIGURA 2. Reducción de la intususcepción por vía abdominal

Una vez finalizada la reducción, se procedió a verificar la funcionalidad del intestino y se resecó la parte necrosada causada por la invaginación, (FIG. 3).

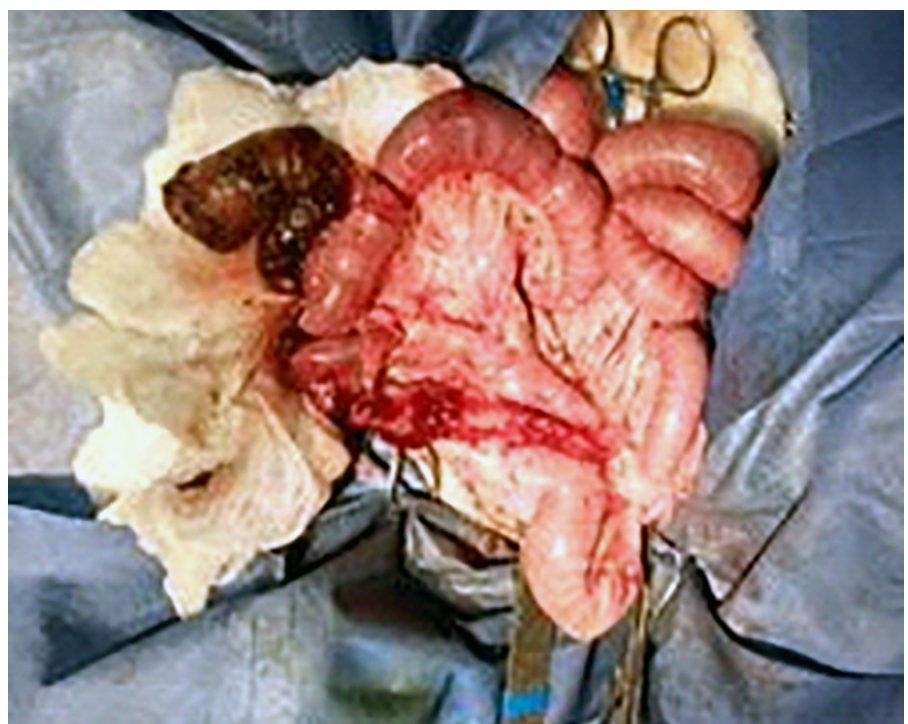

FIGURA 3. Resección de la parte necrosada causada por la intususcepción
Se realizó anastomosis término-terminal, con cuatro puntos de polidioxanona $2 / 0$ con aguja de $1 / 2$ circulo roma (en forma de reloj) y se continuó con poliglactina $910,2 / 0$ con aguja de 1/2 circulo redonda, Se comprobó la permeabilidad del intestino, y se realizó lavado con mezcla de solución salina fisiológica estéril y metronidazol, luego se efectuó el recuento de elementos y agujas, a continuación se ejecutó el cierre de la cavidad por planos con poliglactina 910,1 con aguja de $1 / 2$ circulo punta redonda; y polipropileno $3 / 0$, con aguja de $3 / 8$ de circulo de punta cortante.

Se trasladó al canino nuevamente a hospitalización, para ser monitoreado constantemente, se le ordenó seguir con la medicación de Metronidazol, Ampicilina y Fluimucil. Transcurridos tres d de evolución se produjo el deceso del paciente debido a una isquemia de repercusión.

\section{RESULTADOS Y DISCUSIÓN}

El caso clínico reportado evidenció un paciente sin antecedentes e historial de vacunación que llevó a dar un diagnóstico inicial de gastroenteritis de origen viral, sin sensación de inflamación o dolor a la palpación, por lo que se trató con medicación, hospitalización y observación de evolución; luego de una semana, el paciente sufrió prolapso intestinal ano-rectal, con necrosis avanzada, que aunque se trató quirúrgicamente dio como resultado una necrosis de repercusión intestinal y fallecimiento del paciente.

Ortiz y col. [8] refirieron en su estudio un paciente canino llevado a consulta por diarrea sanguinolenta, decaimiento, inapetencia, tenesmo y prolapso intestinal por el ano en el momento de defecar, de una semana de evolución. El examen clínico arrojó que la patología ameritaba la realización de una colonoscopia o una laparotomía exploratoria sin aprobación de los propietarios, por lo que se le realizó medicación para el parasitismo que presentaba. Al comparar los resultados con el caso clínico descrito se observó similitud en cuanto a sintomatología, y a medicación para el tratamiento de parasitismo como diagnóstico inicial [8].

Una revisión de la literatura realizada por Hernández [4] señala que, las intususcepciones son causas importantes de obstrucción intestinal en perros y que se han relacionado varios factores con el desarrollo de la condición, incluyendo: parasitismo gastrointestinal, cuerpos extraños lineales, enteritis o gastroenteritis aguda, masas intestinales y cirugía abdominal previa, algunos de estos factores son semejantes a los descritos en este reporte de caso. En cuanto al prolapso rectal, el autor indicó que se puede presentar por condiciones que causen tenesmo, tales como: parasitismo, hernias perineales, enfermedades prostáticas, inflamación del recto y ano, tumores, cuerpos extraños, distocia, obstrucción uretral y colitis [4].

Atray y col. [1] describen el caso de tres animales de especie canina con intususcepción doble indicando que ésta puede ocurrir como una secuela de parasitismo intestinal, cuerpos extraños lineales, enteritis viral, masas intestinales y cirugía abdominal previa y síntomas de anorexia, vómitos y diarrea sanguinolenta; al contrastar lo descrito por el autor frente al caso clínico se observó similitud en relación a los siguientes signos clínicos: edad del paciente, d de evolución de la enfermedad, sintomatología y diagnóstico previo [1].

La literatura reporta que la intususcepción puede ser un proceso activo, en el cual el segmento invaginado entra y sale del invaginante. Wiethuchter y col. [11] reportan un caso 
de adenocarcinoma intestinal en canino adulto, que causó una intususcepción a nivel ileocecal; según este reporte, la intususcepción en caninos menores a un año se debe por lo general a antecedentes de parasitismo, en edades avanzadas esta patología puede estar asociada a tumores de tipo cancerígeno. Al relacionar la literatura citada con el caso presentado, donde el paciente era un canino joven se observa similitud en los antecedentes presentados [11].

\section{CONCLUSIONES}

La intususcepción intestinal en pequeños animales es poco frecuente, su manejo requiere precisión en la habilidad diagnóstica preoperatoria y en el manejo intraoperatorio. La literatura científica muestra diversas opciones de tratamiento junto a los diferentes posibles abordajes, sin embargo, se evidencia una mayor predilección en resecciones primarias.

Estas patologías gastrointestinales pueden ser confundidas fácilmente por su clínica con una enteritis, un cuerpo extraño o una neoplasia intestinal, esto debido a la similitud de signos clínicos; es importante recalcar el uso de pruebas diagnósticas más especializadas como los estudios radiográficos con medio de contraste y la ecografía abdominal como medios específicos para determinar la enfermedad.

\section{REFERENCIAS BIBLIOGRÁFICAS}

[1] ATRAY, M; RAGHUNATH, M; SINGH, T; SAINI, NS; Ultrasonographic diagnosis and surgical management of double intestinal intususception in 3 dogs. Can. Vet. J. 53: 860-864. 2012.

[2] ETTINGER, S; FELDAMN, E. Infecciones del tracto digestivo. Tratado de Medicina Interna Veterinaria: enfermedades del perro y el gato. 6ta. Ed. Volumen 2. Buenos Aires (Arg): Editorial Intermedica. Pp 1400-1410. 2007.

[3] GORDON, SC; CONNOR, LM; SWINDELLS, KL; JOHNSON, VS; RAISIS, AL. Intususception following methiocarb toxicity in three dogs. J. Vet. Emerg. Crit. Care. 18(1): 68-74. 2008.

[4] HERNÁNDEZ, CA. Emergencias gastrointestinales en perros y gatos. Rev. CES Med. Vet. Zoot. 5(2): 69-85. 2010.

[5] LUCENA, R; GINEL, P J. Intususcepción intestinal con alteración hepatobiliar grave en un perro. Asoc. Vet. Español Especial. Peq. Anim. 26(1): 19-22. 2006.

[6] MALA, S. Recurrent intussusception in a 14-month-old, spayed, female German shepherd cross. Can. Vet. J. 41: 407-408. 2000.

[7] MURGIA, D. Surgery Of The Small Intestine In Dogs and Cats - Part 2. Anim. Health Trust, Compan. Anim. 18(4): 158-164 2013.

[8] ORTIZ, JF; OSORIO, A; TOBÓN; AM. Intususcepción cecocólica e invaginación del ciego en un canino: reporte de caso. Med. Vet. Zoot. Universidad Nacional de Colombia. 58(2): 99-106. 2011.

[9] PATSIKAS, M; PAPAZOGLOU, LA; MORAITOU, KK. Spontaneous Reduction of Intestinal Intussusception in Five Young Dogs. J. Amer. Anim. Hosp. Assoc. 44: 292-294. 2008.
[10] PRATHABAN, S; RAMPRABHU, MR; SIMON, S. Double intussusception in a dog. Ind. J. Can. Pract. 5: 45-47. 2013.

[11] WIETHUCHTER, CF; LEPE, V; TRONCOSO-TORO, IE; SANDOVAL, A; VILLARROEL, MD. Adenocarcinoma intestinal causante de una intususcepción en un canino. Reporte de un caso. REDVET. 18(9): 1-7. 2017. 